Recepción: 20 / 12 / 2018

Aceptación: 28 / 01 / 2019

Publicación: 20 / 03 / 2019

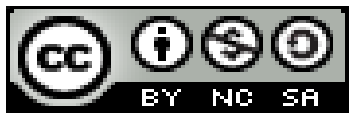

Ciencias de la salud

Artículo de revisión

\title{
Consideraciones preventivas en paciente sometido a cirugía prostática
}

\author{
Preventive considerations in a patient subjected to prostate surgery
}

\section{Considerações preventivas em um paciente submetido a cirurgia de próstata}

Gema M. Barreto-Pincay ${ }^{\mathrm{I}}$ gemitajjbp@hotmail.es

José F. Barreto-Loor ${ }^{\text {II }}$ fernando1984_loor@live.com

Julio D. Cevallos-Villamar III julio-cevallos@hotmail.com

Luis A. Giler-Saltos IV lags-89@hotmail.com

Mary I. Vinces-Zambrano V maryisabelvz@hotmail.es

Hernán D. Toro-Barrera VI hdavidtorob@gmail.com

Correspondencia: gemitajjbp@hotmail.es

I. Médico Cirujano; Residente de la Clínica Sta. Margarita; Residente del Hospital de Especialidades; Portoviejo, Ecuador.

II. Médico Cirujano; Médico General de Primer Nivel de Atención 2; Ministerios de Salud Pública del Ecuador; Portoviejo, Ecuador.

III. Médico Cirujano; Docente en la Universidad Estatal del Sur de Manabí; Departamento de Nivelación; Jipijapa, Ecuador.

IV. Médico Cirujano; Hospital General IESS; Portoviejo, Ecuador.

V. Médico Residente; Hospital General IESS; Médico Residente de UCI Clínica Centeno; Manta, Ecuador.

VI. Médico Cirujano; Médico Residente de UCI Clínica Centeno; Médico Residente de Emergencia y Jefe de Guardia Hospital General IESS; Manta, Ecuador. 


\title{
Resumen
}

Durante el proceso de valoración del paciente debe darse formal cumplimiento en los protocolos con las herramientas necesarias a fin de establecer un consenso en el diagnóstico y tratamiento tanto para la hiperplasia prostática benigna cuya fisiopatología, epidemiología e historia natural no se comprende completamente, del mismo modo para las infecciones de prostatitis tanto agudas o crónicas, de naturaleza casi siempre bacteriana, así como para el cáncer de próstata mismo que es una malignización del tejido prostático, no existe hasta la presente un parámetro único y confiable que permita definir con precisión estas patologías, los síntomas e índices de calidad de vida son parámetros subjetivos y por lo tanto, significativamente variables. El tipo de investigación empleado en el presente trabajo es de tipo bibliográfico ya que fueron utilizados diferentes medios electrónicos para la búsqueda y recopilación de información sobre la temática de estudio. Entre las principales conclusiones a las que se llega con la presente investigación es que es de importancia la consideración preventiva en el autocuidado puesto que esta marca diferencias significativas respecto a la asistencia habitual en la mejora de la sintomatología, mantener periódicamente la correcta de vigilancia, en este sentido es vital. La prevención y cura de la infección mediante el empleo de los tratamientos en las dosis adecuadas y durante el período óptimo. Además, muchos de los problemas están relacionados con la calidad de vida de los individuos afectados.

Palabras claves: Hiperplasia Prostática Benigna; Infecciones de Prostatitis; Cáncer de Próstata; Consideración Preventiva; El Autocuidado; Calidad de Vida.

\begin{abstract}
During the process of patient assessment, protocols must be formally complied with with the necessary tools in order to establish a consensus in the diagnosis and treatment of both benign prostatic hyperplasia whose pathophysiology, epidemiology and natural history are not fully understood, in the same way for acute or chronic prostatitis infections, which are almost always bacterial in nature, as well as for prostate cancer itself, which is a malignisation of the prostate tissue, there is no single and reliable parameter to define these pathologies precisely, the symptoms and indices of quality of life are subjective parameters and, therefore, significantly variable. The type of research used in the present work is of a bibliographic type since different electronic means were used to search and collect information on the subject of study. Among the main conclusions reached with this research is that it is important to consider preventive self-care since this marks
\end{abstract}


Gema M. Barreto-Pincay; José F. Barreto-Loor; Julio D. Cevallos-Villamar; Luis A. Giler-Saltos; Mary I. VincesZambrano; Hernán D. Toro-Barrera

significant differences with respect to the usual assistance in improving symptoms, periodically maintaining the correct surveillance, in this sense is vital. The prevention and cure of the infection by using the treatments in the appropriate doses and during the optimal period. In addition, many of the problems are related to the quality of life of the affected individuals.

Keys words: Benign prostatic hyperplasia; Prostatitis infections; Prostate cancer; Preventive Consideration; Self-care; Quality of life.

\section{Resumo.}

Durante o processo de avaliação do paciente, os protocolos devem ser formalmente cumpridos com as ferramentas necessárias para estabelecer um consenso no diagnóstico e tratamento de ambas as hiperplasias benignas da próstata, cuja fisiopatologia, epidemiologia e história natural não são totalmente compreendidas, da mesma forma Infeç̧ões por prostatite aguda ou crônica, que são quase sempre de natureza bacteriana, bem como para o próprio câncer de próstata, que é uma malignização do tecido da próstata, não há um parâmetro único e confiável para definir precisamente essas patologias, os sintomas e índices de qualidade da vida são parâmetros subjetivos e, portanto, significativamente variáveis. O tipo de pesquisa utilizada no presente trabalho é do tipo bibliográfico, pois diferentes meios eletrônicos foram utilizados para buscar e coletar informações sobre o assunto de estudo. Dentre as principais conclusões desta pesquisa, destaca-se que é importante considerar o autocuidado preventivo, pois isso marca diferenças significativas em relação à assistência usual na melhora dos sintomas, mantendo periodicamente a correta vigilância, neste sentido, é vital. A prevenção e cura da infecção usando os tratamentos nas doses apropriadas e durante o período ótimo. Além disso, muitos dos problemas estão relacionados à qualidade de vida dos indivíduos afetados.

Palavras chaves: Hiperplasia benigna da próstata; Infecções por prostatite; Câncer de próstata; Consideração Preventiva; Autocuidado; Qualidade de vida.

\section{Introducción.}

En la enfermedad prostática se han descrito tres conceptos de entidades patológicas más frecuentes relacionadas con la próstata como son las la hiperplasia prostática benigna, prostatitis agudas y crónicas y el propio cáncer de próstata. 

Gema M. Barreto-Pincay; José F. Barreto-Loor; Julio D. Cevallos-Villamar; Luis A. Giler-Saltos; Mary I. VincesZambrano; Hernán D. Toro-Barrera

La hiperplasia prostática benigna (HPB) es una patología de alta prevalencia en la consulta urológica. Es el tumor benigno más frecuente en los varones mayores de 60 años y representa la segunda causa de intervención quirúrgica (Chicharro-Molero, y otros, 1998).

La Hiperplasia Benigna de Próstata (HBP) es una patología compleja en la cual el crecimiento glandular y la interacción de este proceso con el control dinámico de la micción contribuyen al establecimiento de los síntomas de prostatismo que aparecen en los hombres hacia la quinta década de vida. Las implicancias clínicas de la investigación de los mecanismos involucrados en la etiología y patogénesis de la HBP pueden conducir al desarrollo de estrategias que previenen y, consecuentemente, evitan el desarrollo de esta enfermedad (González Calvar, Salcedo, \& Martínez Mangini, 2005).

Una de las causas predisponentes que provocan obstrucción urinaria del tracto inferior es la hiperplasia prostática benigna, la cual es una entidad prevalente en la atención primaria y se considera el principal motivo de consulta por problemas urológicos en el hombre, esta entidad de manera clásica ha sido manejada en forma casi exclusiva por el urólogo, debido a que parte de su tratamiento se basa en técnicas quirúrgicas esta enfermedad se considera como la segunda causa de cirugía a nivel mundial. Sin embargo en la actualidad el médico de familia puede ocupar un rol activo en el diagnóstico y el tratamiento de muchos pacientes con este problema para de esta manera evitar la progresión a graves complicaciones (Esteban, 2013).

La hiperplasia benigna de la próstata (HBP) o la hiperplasia prostática benigna (HPB) es una condición médica caracterizada por el aumento benigno de la próstata, que normalmente se inicia en hombres de más de 40 años. Desde el punto de vista histológico, la HBP se caracteriza por la hiperplasia de las células del estroma y del epitelio de la glándula prostática, resultando en el aumento volumétrico de ésta y en la posibilidad de interferencia en el flujo normal de orina causada por la compresión de la uretra prostática y por la relajación inadecuada del cuello vesical (Averbeck, y otros, 2010).

La disminución en la producción de testosterona comienza alrededor de los 50 años. El declive de la función testicular induce una descompensación de los factores que regulan la próstata. Cuando los andrógenos decaen se elevan los factores estimuladores del crecimiento, produciéndose el consiguiente aumento prostático (Grossfeld \& Coakley, 2000). 
La hiperplasia prostática benigna (HPB) representa la enfermedad prostática más común en hombres de la tercera edad; a nivel mundial se estima que el 55\% de los hombres entre 55 y 70 años tienen evidencia histológica de la enfermedad, y que para los 90 años esta cifra se eleva al 90\%. Un50\% desarrollará sintomatología clínica de la enfermedad. Dadas las implicaciones en las poblaciones y en los individuos mismos, ha existido un interés creciente en estudios epidemiológicos con factores de riesgo modificables para el cáncer de próstata, tales como dieta, ejercicio, metabolismo de la glucosa y obesidad. Esta última en particular representa una epidemia en naciones industrializadas, con una prevalencia del 34.4\% (Parsons, Sarma, McVary, \& Wei, 2013).

En el hombre en proceso de envejecimiento debido a la presencia de diversos factores. En primer lugar, la dificultad técnica para establecer un diagnóstico certero en relación a una deficiencia androgénica verdadera acompañada del envejecimiento, o de una "andropausia" como tal; en segundo lugar, el potencial riesgo de desencadenar un cáncer prostático, o exacerbar los síntomas obstructivos de una hiperplasia prostática preexistente, debido a la influencia androgénica que durante años se le ha relacionado (Wiechers \& Cuéllar, 2007).

En México, la incidencia y la prevalencia de afecciones de la próstata se han incrementado, lo que se explica por el aumento de la expectativa de vida, que da la oportunidad a los hombres a desarrollar STUI. Uno de los métodos utilizados para ayudar a diagnosticar esta dolencia es el PSA. Actualmente no existen datos provenientes de pacientes mexicanos sobre la relación que existe entre los niveles de PSA y la HPB, pero datos obtenidos de otras poblaciones demuestran que existe una fuerte relación entre los niveles de PSA y el volumen prostático, siendo este último un marcador objetivo del grado de HPB (García, 2014).

El antígeno prostático específico (PSA) es una glucoproteína producida por el epitelio prostático en forma exclusiva, lo que lo ha distinguido como marcador no invasivo, sensible y específico de enfermedad de la glándula prostática, incluyendo el cáncer prostático, sin embargo la HPB así como la prostatitis también elevan el nivel de PSA3.Su medición está indicada en pacientes mayores de 40 años con antecedentes familiares directos de cáncer de próstata y en todos aquellos mayores de 45 años con HPB para el diagnóstico diferencial del cáncer prostático (García, 2014).

El descubrimiento del antígeno prostático y su extenso uso en las últimas 2 décadas han influido de forma importante en la manera en la que el cáncer de próstata es manejado así como en su 
Gema M. Barreto-Pincay; José F. Barreto-Loor; Julio D. Cevallos-Villamar; Luis A. Giler-Saltos; Mary I. VincesZambrano; Hernán D. Toro-Barrera

seguimiento. A pesar de esto existen limitaciones acerca del screening del cáncer de próstata que ha llevado a recomendaciones polémicas en cuanto a quién realizarlo y a qué edad iniciar el screening. Quizá el factor más importante es la inhabilidad para establecer el punto de corte de un antígeno prostático normal como factor predictivo (Aguilar-Barradas, y otros, 2010).

La mayoría de los cánceres de próstata son detectados mediante biopsia transrectal posterior a un valor de antígeno prostático elevado. El uso elevado de este recurso ha llevado a una detección en etapas tempranas de la enfermedad así como a una reducción de la mortalidad. A pesar de dichas circunstancias, el antígeno prostático tiene baja especificidad y reducida sensibilidad por debajo de un valor de corte específico. Otro gran problema es que el antígeno prostático específico (APE) puede ser alterado por factores no relacionados con el cáncer. El entendimiento de estos factores y su manera de relacionarse incrementará la utilidad del APE en el screening del cáncer de próstata (Aguilar-Barradas, y otros, 2010).

Mientras que el siglo XX se ha caracterizado por el crecimiento de la población, el siglo XXI será el del envejecimiento de la misma como consecuencia de la inversión de la pirámide poblacional. El aumento en la expectativa de vida junto con la exigencia de una vida de calidad, supone un aumento en la demanda sanitaria y asistencial en el anciano. Por lo tanto, ya que la hiperplasia benigna de próstata (HBP) es una patología frecuente e inherente a la edad estamos asistiendo a un cambio en el patrón demográfico del paciente urológico. El efecto de la edad así como de las comorbilidades en la morbi-mortalidad perioperatoria en el tratamiento quirúrgico de la HBP ha sido ampliamente debatido. Con este estudio se pretende valorar el efecto de la edad de los pacientes en la morbimortalidad y en el resultado del tratamiento quirúrgico de la HBP (García Torrelles, y otros, 2007).

\section{Metodología.}

El presente artículo tiene una revisión específica, se ha cumplido con una investigación de literatura en diferentes bases de datos en donde se hizo la exploración más semejante, para la realización de la actual investigación. Se tomó en cuenta información confiable sobre trabajos de Consideraciones preventivas en paciente sometidos a cirugía prostática, la misma se obtuvo de libros electrónicos, consultas electrónicas, artículos científicos y revistas. 


\section{Desarrollo.}

\section{Patologías de la enfermedad prostática}

En la enfermedad prostática se han descrito tres conceptos de entidades patológicas más frecuentes relacionadas con la próstata como son las la hiperplasia prostática benigna, prostatitis agudas y crónicas y el propio cáncer de próstata:

\section{Hiperplasia prostática benigna}

La fisiopatología, epidemiología e historia natural de la hiperplasia prostática benigna (BPH), no se comprende completamente; sin embargo, el desarrollo de instrumentos confiables para medir la severidad de los síntomas, agrandamiento de la próstata y La obstrucción de la salida de la vejiga ha permitido importantes avances en su elucidación (Lepor, 2004).

La HPB constituye un problema de salud pública, en función de la alta prevalencia en la población masculina y de los problemas relacionados con la calidad de vida de los individuos afectados (Averbeck, y otros, 2010).

El término hiperplasia prostática benigna se ha usado tradicionalmente para describir una constelación de síntomas de vaciamiento obstructivos e irritativos que ocurren en los hombres a medida que envejecen. Dicha sintomatología puede deberse a una variedad de causas, incluida la ampliación de la próstata. Por lo tanto, el término síntomas del tracto urinario inferior ha reemplazado a la HPB para describir este complejo de síntomas. La evaluación y el tratamiento de los LUTS siguen siendo una parte importante de la práctica de la urología en los Estados Unidos, así como un componente importante de la utilización de los recursos médicos (Grossfeld \& Coakley, 2000).

Los sintomas del tracto urinario inferior pueden estar asociados a un aumento del volumen de la glándula prostática, a la obstrucción de salida del tracto urinario inferior $\mathrm{y} / \mathrm{o}$ cambios histopatológicos caracterizados por la hiperplasia glandular y/o estromal. Esta relación de síntomas no implica necesariamente una relación causal, aunque la causa más frecuente de la presencia de estos síntomas y de la obstrucción referida es el aumento de la glándula prostática (Scher, 2012). Los síntomas del tracto urinario inferior (STUI) en los hombres constituyen un aspecto clave en la 
Gema M. Barreto-Pincay; José F. Barreto-Loor; Julio D. Cevallos-Villamar; Luis A. Giler-Saltos; Mary I. VincesZambrano; Hernán D. Toro-Barrera

atención de servicios urológicos, ellos se centran en la gravedad de los síntomas y dan prioridad al grado en que molestan al paciente (Drake, 2016).

El desarrollo de síntomas del tracto urinario inferior (LUTS) en el envejecimiento masculino está influenciado en cierto grado por la gravedad de la obstrucción de la salida de la vejiga y agrandamiento prostático. A pesar del desarrollo de LUTS, salida de vejiga, obstrucción, y la BPH son dependientes de la edad, no son necesariamente causales relacionado. Hay muchos otros factores involucrados en la fisiopatología de TUERCA. Los parámetros clínicamente importantes de progresión de la enfermedad en hombres con LUTS moderados a severos y bajas tasas de flujo pico son síntomas, la progresión y el desarrollo de la retención urinaria aguda (AUR), los El riesgo de AUR está relacionado con el nivel basal de antígeno específico de la próstata en suero y volumen de la próstata. En los hombres con agrandamiento de la próstata moderado, el riesgo de AUR parece ser lo suficientemente alto como para justificar la intervención con una $5 \alpha$-reductasa Inhibidor para reducir este riesgo (Lepor, 2004).

La hiperplasia benigna de la próstata se define histológicamente. El tamaño de la glándula prostática aumenta y determina una obstrucción del flujo urinario que origina unos síntomas del tracto urinario inferior. Rodriguez, et al., (2002).

La HBP se caracteriza histológicamente por el crecimiento progresivo de la glándula prostática debido a un proceso proliferativo no maligno que incluye tanto elementos epiteliales como estromales. El proceso de hiperplasia es multifocal y muestra una histología abigarrada con una proporción variable de nódulos estromales y de hiperplasia glandular. La frecuencia de las alteraciones benignas y malignas de la próstata aumenta con el envejecimiento. Las necropsias de varones en el octavo decenio de vida indican la presencia de cambios hiperplásicos en más del $90 \%$ de los casos y alteraciones cancerosas en más del 70\%. La alta prevalencia de estas enfermedades en la población anciana, que tiene otras causas de morbilidad y mortalidad, obliga a plantear el diagnóstico y tratamiento en conformidad con los riesgos, lo cual puede lograrse si estas enfermedades se consideran como una sucesión de estadios (Scher, 2012).

Presentación clínica y evaluación inicial. Desde el punto de vista clínico, los pacientes portadores de HBP pueden presentar síntomas clásicamente reconocidos como relacionados con el almacenamiento o el vaciado vejiga. El chorro de orina irregular y intermitente constituye un 
síntoma de alta prevalencia en la HBP, pudiendo variar en períodos del día ya lo largo del tiempo. Huesca es la denominación dada al aumento del intervalo entre el inicio del deseo miccional y la ocurrencia efectiva del flujo urinario. El goteo terminal puede ocurrir por permanencia de pequeño volumen urinario en la uretra bulbar, por falta de mantenimiento de la presión del detrusor durante toda la micción (Averbeck, y otros, 2010).

La polaquiuria se puede definir como más de ocho micciones al día, mientras que la nicturia es el aumento del número de micciones la noche. Se hace necesaria la distinción entre nocturia y la poliuria nocturna en la población anciana; poliúria nocturna si se caracteriza por la inversión del ritmo normal de producción de orina (mayor producción de orina por la noche), que requiere investigación clínica para posibles comorbilidades asociadas (insuficiencia renal crónica, insuficiencia cardiaca, insuficiencia cardíaca hepática, síndrome nefrótico, etc.). Urgencia e incontinencia de urgencia derivan de la presencia de contracciones involuntarias del detrusor, pudiendo reflejar la respuesta de la musculatura vesical a la obstrucción crónica. Se mantiene la retención urinaria aguda clásicamente como evento final de la obstrucción crónica causada por la HBP (Averbeck, y otros, 2010).

La protrusión prostática intravesical (PPI) es una manifestación de hiperplasia prostática benigna caracterizada por el crecimiento excesivo del lóbulo medial prostático en la vejiga, que produce obstrucción de la salida de la vejiga y almacenamiento relacionado y síntomas de evacuación (Gandhi, y otros, 2018).

Diversos estudios realizados hasta la fecha han demostrado que la HBP es una enfermedad de carácter progresivo y con riesgo variable entre unos y otros pacientes. Los factores clínicos predictivos de progresión de la HBP no están todavía definitivamente esclarecidos, pero se han relacionado preferentemente con el volumen prostático y los niveles plasmáticos del antígeno específico prostático (PSA) en el momento del diagnóstico inicial y con el empeoramiento de la de puntuación de síntomas respecto a las cifras basales. Por otro lado, también entre los criterios de progresión se han referido la reducción del flujo urinario máximo y la disminución de la calidad de vida relacionada con los síntomas de HBP a lo largo del tiempo (Chute, y otros, 1993).

Existen factores preoperatorios y nomogramas bien establecidos que confieren un riesgo para recurrencia bioquímica y pronóstico en pacientes sometidos a prostatectomía radical como son el 
Gema M. Barreto-Pincay; José F. Barreto-Loor; Julio D. Cevallos-Villamar; Luis A. Giler-Saltos; Mary I. VincesZambrano; Hernán D. Toro-Barrera

antígeno prostático, el grado en la escala de Gleason y el estadío clínico (cTNM). Si bien en algunas series han referido mayor dificultad técnica y morbilidad en los pacientes con cirugía prostática previa, no existen factores de riesgo establecidos para determinar el riesgo de potenciales complicaciones tempranas y a largo plazo en los pacientes sometidos a prostatectomía radical. Entre las complicaciones durante éste procedimiento están: la hemorragia, que en promedio va de $200 \mathrm{~mL}$ a $1500 \mathrm{~mL}$ dependiendo de la técnica quirúrgica y la duración de la cirugía; la lesión rectal, que ocurre en entre $1 \%$ a $3 \%$ de los pacientes, dependiendo la serie (Zael, y otros, 2010).

Como factores predisponentes se mencionan: radioterapia previa, antecedente de cirugía rectal y resección transuretral previa. La lesión del nervio obturador y la lesión ureteral son complicaciones muy raras pero que hay que tomar en cuenta. Otra complicación temprana asociada es la trombosis venosa profunda, la cual incurre en aproximadamente en $1.6 \%$ de los pacientes y que se constituye como factor de riesgo para eventos tromboembólicos, como la tromboembolia pulmonar, principal causa de muerte posoperatoria. Este riesgo disminuye con la movilización posoperatoria temprana. La infección del sitio quirúrgico puede presentarse hasta en $10 \%$ de los pacientes, la fuga o fístula urinaria en 3\% y el linfocele en menos de 1\% de los casos (Zael, y otros, 2010).

Las complicaciones tardías descritas son la contractura del cuello vesical $(0.5 \%$ a $10 \%)$; la incontinencia, hasta en $8 \%$ de los pacientes radicalizados, después de 24 meses; los casos severos de incontinencia $(<1 \%)$, pueden requerir de un esfinter artificial. La disfunción eréctil se presenta en general en $12 \%$ a $30 \%$, con una relación directamente proporcional a la edad. La tasa general de complicaciones quirúrgicas va de $5 \%$ a $7 \%$; la edad avanzada es el factor más frecuentemente asociado a las complicaciones (Zael, y otros, 2010).

Valorando grupos de pacientes de diferente edad, homogéneos en cuanto al tipo de cirugía y la comorbilidad preoperatoria ASA, no se encuentran diferencias significativas en la aparición de complicaciones, urológicas, generales y en el seguimiento, ni en la estancia media postoperatoria. Con un nivel de satisfacción elevado tras el tratamiento quirúrgico. Por lo tanto las diferencias previas observadas pueden ser debidas a otras variables y no a la edad cronológica per se entendida como factor de riesgo clínico, pudiendo beneficiarse estos pacientes de un tratamiento quirúrgico resolutivo que mejore su calidad de vida, en lugar del "watchful waiting” condenándolos a una 
sonda permanente o a la limitante sintomatología de un prostatismo severo (García Torrelles, y otros, 2007).

Un estudio comparando el manejo expectante (Wachful Waiting - WW) y RTU de la próstata, en los hombres con síntomas moderados, demostró que aquellos pacientes sometidos a cirugía mejoraron la función de la vejiga en relación al grupo de WW (tasas de flujo y volumen residual postmiccional). En el grupo de WW, el 36\% de los pacientes necesitaron cirugía en 5 años. Aproximadamente el $85 \%$ de los hombres permanecerán en el grupo de WW en 1 año y alrededor del 65\% en 5 años (Averbeck, y otros, 2010).

La PR es un procedimiento seguro, bien tolerado y con una baja tasa de complicaciones. Es necesario conocer las complicaciones potenciales de este procedimiento para tomar las decisiones terapéuticas adecuadas en su resolución durante el transoperatorio o en el posoperatorio temprano. En nuestro análisis, no se encontró ningún factor relacionado con las complicaciones tempranas de la prostatectomía radical. Consideramos que el factor más importante que puede disminuir las complicaciones tempranas de la prostatectomía radical es una adecuada técnica quirúrgica, así como una adecuada experiencia en el procedimiento (Zael, y otros, 2010).

El autocuidado marca diferencias significativas respecto a la asistencia habitual en la mejora de la sintomatología. Los elementos que se consideran claves son: la información sobre la enfermedad del paciente, la transmisión de la tranquilidad de que el cáncer no es la fuente de sus síntomas urinarios, y marcar una estructura correcta de vigilancia periódica (Brown, y otros, 2007).

\section{Exámenes recomendados}

Exámenes de laboratorio recomendados por el Consejo Internacional del Mónaco (1995) y Paris (1997) y homologados por la OMS tienen como objetivo establecer los criterios mínimos de evaluación, han sido considerados en la evaluación inicial con determinación obligatoria: (Holtgrewe, Nielsen, \& Carlsson, 1997)

- Análisis de orina para determinar si el paciente tiene hematuria, proteinuria, piuria u otros hallazgos patológicos; 
Gema M. Barreto-Pincay; José F. Barreto-Loor; Julio D. Cevallos-Villamar; Luis A. Giler-Saltos; Mary I. VincesZambrano; Hernán D. Toro-Barrera

- Dosificación sérica de creatinina para detectar si el paciente tiene insuficiencia renal. Cuando la tasa de creatinina es elevada se recomienda el estudio de imagen del aparato urinario superior;

- Por esta razón la dosificación sérica del PSA es recomendada en la evaluación inicial de enfermos con por lo menos 10 años de esperanza de vida y en aquellos a quienes se les diagnostique cáncer de próstata, ya que una vez establecido va a condicionar el tratamiento.

Exámenes de imagen, Ultrasonografía supra púbica: auxiliar importante en el diagnóstico de litiasis, tumores o divertículos, y permite la determinación del espesor de la pared vesical y del residuo posmiccional. Sin embargo, estos parámetros tienen una elevada variabilidad individual. El residuo posmiccional se considera anormal si es persistentemente mayor a 100 a $120 \mathrm{ml}$ (Holtgrewe, Nielsen, \& Carlsson, 1997).

Aunque la IPP se puede identificar a través de una variedad de modalidades de imágenes, se detecta fácilmente a través de la ecografía transrectal (TRUS). El no poder detectar la IPP rápidamente por TRUS puede resultar en síntomas refractarios de hiperplasia prostática benigna, ya que la condición puede no responder a la terapia típica con antagonistas de los receptores adrenérgicos $\alpha 1$. Además, según el grado, la IPP puede influir en los resultados y las complicaciones de las prostatectomías (Gandhi, y otros, 2018).

Los hallazgos ecográficos de IPP que miden más de $10 \mathrm{~mm}$ se correlacionan fuertemente con la IVO en hombres con LUTS y BPH en comparación con otros parámetros de ultrasonido de la próstata, vejiga urinaria y tasas de flujo urinario. El IPP es un parámetro anatómico que no requiere micción, y se detecta fácilmente con ultrasonido transabdominal y transrectal. Sin embargo, a los valores de PPI inferiores a $10 \mathrm{~mm}$, el método principal para detectar la IVO sigue siendo el estudio de presión / flujo (Krivoborodov, Efremov, \& Bolotov, 2017a).

La protrusión prostática intravesical y el índice de resistencia son parámetros útiles para predecir la obstrucción de la salida de la vejiga en pacientes con síntomas del tracto urinario inferior que sugieren hiperplasia prostática benigna. En la práctica clínica, la combinación de protrusión prostática intravesical e índice de resistencia en la ecografía puede ser un diagnóstico de obstrucción de la salida de la vejiga (Suzuki, Otsuka, \& Ozono, 2016). 
El examen digital de la próstata es imprescindible en hombres con STUI, por dos motivos. Primero, porque puede ayudar a evaluar la posibilidad de neoplasia prostática. Además, ayuda a estimar el volumen prostático, el que es determinante para la elección de la terapia a ser instituida (De la Rosette, y otros, 2006).

Después de la revisión de la literatura, parece que no se justifica la realización de imágenes de rutina del tracto urinario superior en pacientes con LUTS o BPH. El uso selectivo de dichas pruebas de imagen en pacientes con HPB y hematuria, evidencia de laboratorio de insuficiencia renal (BUN elevada o creatinina), o antecedentes de infección del tracto urinario, urolitiasis, cirugía previa del tracto urinario o enfermedad renal adquirida o congénita, sigue estando indicado (Grossfeld \& Coakley, 2000).

La imagen local de la próstata se puede realizar con RM o TRUS. Aunque la RM proporciona una excelente resolución de la anatomía prostática interna, la información con respecto a la proporción de tejido glandular a estromal en la próstata y una estimación precisa del volumen de próstata, su uso en pacientes con BPH está limitado por su alto costo y limitada disponibilidad. En contraste, la TRUS sigue siendo una herramienta importante en la evaluación de pacientes con enfermedad prostática. Al igual que en la RM, TRUS proporciona excelentes imágenes de la anatomía prostática interna y una estimación precisa del volumen de la próstata antes del tratamiento. Además, esta modalidad de imagen no es invasiva, es rentable, se adapta fácilmente al uso en la oficina y es capaz de proporcionar orientación para la biopsia transrectal de próstata (Grossfeld \& Coakley, 2000).

Con la intención de uniformizar la evaluación del paciente portador o no de síntomas relacionados con la HBP, se han desarrollado cuestionarios. En estos casos cabe destacar el I-PSS (International Prostate Symptom Score - Tabla 1), derivado de la puntuación de la American Urological Association (AUA), descrito por Barry en 1990. Hoy es el método más difundido y aceptado internacionalmente con ese propósito. Es compuesto por 7 cuestiones con escores que, cuando sumados, reflejan acuradamente la intensidad de los STUI en el último mes, además de una octava cuestión, que evalúa calidad de vida relacionada con los síntomas. Cuando se suman las primeras 7 preguntas, puntuaciones de 0 a7 indican síntomas leves, 8 a 19 moderados, y 20 a 35 graves. Cabe señalar que este cuestionario fue validado para el idioma portugués, siendo ampliamente empleado en nuestro medio (Averbeck, y otros, 2010). 
Gema M. Barreto-Pincay; José F. Barreto-Loor; Julio D. Cevallos-Villamar; Luis A. Giler-Saltos; Mary I. VincesZambrano; Hernán D. Toro-Barrera

La determinación del antígeno prostático específico (PSA) es recomendable, habida cuenta de que la HBP ocurre en edades similares a la de la neoplasia prostática, aspecto relevante cuyo diagnóstico diferencial se hace necesario por el impacto en la conducta terapéutica que se va a instituir. Como complicaciones relacionadas con la obstrucción infravesical secundaria a la HBP, podemos citar hidronefrosis e insuficiencia renal post-renal, así como litiasis vesicular e infecciones urinarios de repetición. Por lo tanto, se recomienda que la dosis de la creatinina sérica sea solicitada a todo paciente candidato al tratamiento quirúrgico de la HBP (Averbeck, y otros, 2010).

Exámenes endoscópicos, La uretrocistoscopia puede ser indicación en situaciones específicas de la patología vesical y uretral como neoplasias vesicales y estenosis de la uretra. Por lo demás puede auxiliar en la decisión terapéutica quirúrgica (Casado \& Moyano, 2011).

La uretrocistoscopia puede ser recomendada antes del tratamiento quirúrgico, para excluir otras patologías y evaluar el tamaño y forma de la próstata, que pueden influir en la modalidad de tratamiento elegida (prostatectomía versus resección transuretral de la próstata) De la Rosette, et al., (2006). Pacientes con HBP u otras causas de obstrucción infravesical (por ejemplo, la estenosis de uretra) pueden desarrollar ciertos las señales que pueden ser evaluadas por la uretrocistoscopia, indicando la presencia de obstrucción, que pueden incluir: aumento visible de la glándula prostática, signos de hipertrofia detrusora con trabeculaciones y formación de divertículos, cálculos vesiculares y residuo post-miccional elevado (Averbeck, y otros, 2010).

Exámenes urodinámicos, La urofluxometría es un método de diagnóstico recomendado en la evaluación de los pacientes con STUI y es un examen obligatorio antes del tratamiento quirúrgico de la HBP. De la Rosette, et al., (2006). A través de este método se puede evaluar el volumen orinado, tasa de flujo máximo (Qmax), promedio de flujo (Qave) y el tiempo para el Qmax. Grino, et al., (1993). La obstrucción infravesical solamente se puede diagnosticar con el estudio flujo-presión (estudio urodinámico) y las tasas de flujo deben interpretarse de manera cuidadosa, pues hombres ancianos con STUI tienen alteraciones urodinámicas relacionadas con la edad (Berry, Coffey, Walsh, \& Ewing, 1984).

Urofluxometria es un registro eléctrico del debito miccional. No es un examen invasivo que tiene por finalidad demostrar la existencia de una obstrucción urinaria. Está recomendado en la 
evaluación diagnostica inicial de enfermos con LUTS y en la evaluación de los resultados durante y post tratamiento (Berry, Coffey, Walsh, \& Ewing, 1984).

Sin embargo, Los hombres con un Qmax inferior a $10 \mathrm{~mL} / \mathrm{seg}$ es más que probable que tengan obstrucción infravesical y, consecuentemente, constituyen el grupo que presenta mejores resultados con el tratamiento quirúrgico. Hombres con STUI y Qmax normal tienen más probabilidades de presentar síntomas no asociados a la HBP. De la Rosette, et al., (2006). El estudio flujo-presión se consideró prueba diagnóstica opcional por las entidades urológicas internacionales. Este estudio no posee validez para predecir el resultado del tratamiento clínico para HBP, pero tiene alta validez para predecir el éxito del tratamiento quirúrgico (Averbeck, y otros, 2010).

La obstrucción infravesical (OIV) es una característica importante del estado funcional del tracto urinario inferior masculino. Se cree que la IVO confirmada por los resultados del estudio de presiónflujo justifica el cambio de un tratamiento médico a uno quirúrgico de los síntomas del tracto urinario inferior (LUTS). La protrusión prostática intravesical (IPP, por sus siglas en inglés) es un nuevo indicador para la detección de IVO secundaria a hiperplasia prostática benigna (HPB). Este indicador tiene varias ventajas sobre otros métodos no invasivos para evaluar la OIV. Los hallazgos iniciales sobre la relación entre la IPP y la IVO sugieren la viabilidad de su uso clínico como herramienta de detección en hombres con síntomas obstructivos de evacuación (Krivoborodov, Efremov, \& Bolotov, Protrusión prostática intravesical en el diagnóstico de obstrucción infravesical en hombres con hiperplasia prostática benigna, 2017b).

La evaluación inicial del paciente con HBP incluye anamnesis con aplicación del score de síntomas prostáticos (IPSS), examen físico con tacto rectal, evaluación de laboratorio (PSA sérico, examen de orina y función renal), además de métodos de imagen y la urodinámica para casos seleccionados (Averbeck, y otros, 2010).

\section{Tratamiento en pacientes}

Actualmente, la indicación de tratamiento en pacientes con LUTS se basa con mayor frecuencia en mediciones subjetivas de la gravedad de los síntomas y la molestia. En consecuencia, la imagen no desempeña un papel importante en la evaluación de tales pacientes. Los datos recientes sugieren que el tamaño de la glándula prostática puede predecir qué pacientes con LUTS desarrollarán síntomas y 
Gema M. Barreto-Pincay; José F. Barreto-Loor; Julio D. Cevallos-Villamar; Luis A. Giler-Saltos; Mary I. VincesZambrano; Hernán D. Toro-Barrera

complicaciones progresivos. Además, tanto el tamaño de la próstata como la composición histológica de la HPB pueden ayudar a seleccionar pacientes para opciones de tratamiento específicas. Por lo tanto, las imágenes radiológicas pueden eventualmente desempeñar un papel más importante en el diagnóstico y tratamiento de los LUTS en el futuro (Grossfeld \& Coakley, 2000).

\section{Tratamiento expectante}

Muchos hombres con STUI no mencionan daño significativo en la calidad de vida y, de esa forma, podrían ser observados. Sin embargo, todos los pacientes con STUI deben ser evaluados antes de iniciar cualquier modalidad de tratamiento, para identificar aquellos con complicaciones, que podrían beneficiarse de la intervención terapéutica. Hombres con síntomas leves a moderados, sin evidencias de complicaciones asociadas, y que no se sienten muy incomodados en relación con los STUIs, pueden ser tratados de manera expectante. El motivo por el cual algunos hombres presentan deterioro de los síntomas y otros no todavía no está bien entendido. El perjuicio a la calidad de vida (grado de insatisfacción del paciente) y el volumen residual post-miccional parecen ser los mejor predictores para la falla del manejo expectante (Averbeck, y otros, 2010).

\section{Tratamiento farmacológico}

El enfoque terapéutico reside básicamente en tres clases: los inhibidores de la 5-alfa-reductasa, los alfa-bloqueadores y los agentes las hierbas medicinales. Los distintos aspectos de estas clases de medicamentos se analizarán a continuación: (Averbeck, y otros, 2010)

a) Inhibidores de la 5-alfa-reductasa.

Esta clase de medicamentos actúa en la enzima 5-alfa-reductasa, inhibiendo la producción de dihidrotestosterona (DHT). La finasterida puede reducir el tamaño de la próstata en 20 a 30\%; puede mejorar la puntuación de síntomas en aproximadamente $15 \%$ y puede, también, mejorar la tasa de flujo urinario de 1,3 a 1,6 ml / seg., (Andersen, y otros, 1995).

Datos de 3 estudios multicéntricos, placebo-controlados, en 4.222 hombres, mostraron que pacientes con próstatas mayores y altos niveles de PSA están en riesgo aumentado para desarrollar retención urinaria y, de esta forma, presentan un mayor beneficio con el empleo de la finasterida (Marberger, y otros, 2000). 
Otro importante beneficio de la finasterida en la práctica urológica es el tratamiento de la hematuria asociada al HBP. Varios estudios confirmaron esta alternativa para los pacientes con hematuria debido a la HBP y que no presentaban obstrucción significativa ni evidencia de adenocarcinoma prostático (FOLEY, y otros, 2000).

Varios estudios concluyeron que la finasterida reduce significativamente la ocurrencia de retención urinaria y la necesidad de tratamiento quirúrgico en los pacientes con HBP. Los efectos colaterales se refieren principalmente a la función sexual. Según el estudio PLESS, los efectos adversos se han reportado: disminución de la libido $(6,4 \%)$, impotencia $(8,1 \%)$, disminución del volumen del eyaculado $(3,7 \%) \mathrm{y}$, en menos del $1 \%$ de los pacientes, otros trastornos, como rash cutáneo, ginecomastia y mastalgia (Roehrborn, y otros, 2000).

Solamente en los valores con SVUI y próstatas grandes se debe considerar la utilización de los inhibidores de la $5 \alpha$-reductasa. Dichos inhibidores dado su acción lenta solo están indicados para el tratamiento a largo plazo (muchos años). Su efecto sobre la concentración del PSA debe tenerse en cuenta para el cribado para el cáncer de próstata. El uso de finasterida podría disminuir el riesgo de hemorragia en la cirugía transuretral de próstata por sus efectos sobre la vascularización de la misma (Donohue, y otros, 2002).

Se sabe que la finasterida disminuye los niveles séricos de PSA. Así, la posibilidad de que la finasterida enmascara la detección precoz del adenocarcinoma de próstata fue cuestionada. Un año de tratamiento con finasterida ( $5 \mathrm{mg} /$ día) disminuye el PSA sérico en un 50\%. De esta forma, se necesita calcular el PSA ajustado para hacer consideraciones sobre la posibilidad de una neoplasia prostática (PSA x 2). La finasterida suprime la dihidrotestosterona sérica (DHT) en alrededor del $70 \%$ y en la próstata en un 90\%. La DHT remanente es el resultado de la actividad de la 5-alfareductasa tipo 1. La dutasterida es un nuevo medicamento que suprime las isoenzimas tipo 1 y 2 de la 5-alfa-reductasa; en consecuencia, la DHT sérica disminuye en un 90\% (Bartsch, Rittmaster, \& Klocker, 2002).

De los resultados de 4 ensayos clínicos aleatorizados, doble ciegos, tres de estos estudios fueron placebo-controlados y demostraron que la dutasterida puede reducir el volumen prostático en alrededor del 26\%, mejorar los síntomas y la tasa de flujo urinario y reducir la incidencia de retención urinaria (así como la necesidad de cirugía para el tratamiento de HBP). La dutasterida 
Gema M. Barreto-Pincay; José F. Barreto-Loor; Julio D. Cevallos-Villamar; Luis A. Giler-Saltos; Mary I. VincesZambrano; Hernán D. Toro-Barrera

muestra eficacia y tolerabilidad similar a la finasterida, pero más estudios aleatorizados son necesarios para evaluar el medicamento. (Andriole \& Kirby, 2003), (Roehrborn, Boyle, Nickel, Hoefner, \& Andriole, 2002).

\section{b) Alfa-bloqueadores}

Un gran número de alfa-bloqueadores está disponible en el mercado (tamsulosina, alfuzosina, doxazosina, prazosina, terazosina). Ellos tienen eficacia y perfil de efectos colaterales similar. Los alfa-bloqueadores actúan a través antagonismo de los receptores adrenérgicos responsables tónico muscular liso dentro de la próstata y en el cuello vesical. Los alfa-bloqueadores pueden tomarse por vía oral y La dosis depende de la vida media de la droga. Tamsulosina, alfuzosina, terazosina y doxazosina tienen la ventaja de la administración única diaria. No es incoherente ofrecer un período de tratamiento con alfa-bloqueador para todos los hombres con STUIs no complicados (De la Rosette, y otros, 2006).

La duración ideal del tratamiento ha sido debatida. Los síntomas pueden mejorar dentro de 48 horas. Una reevaluación del IPSS requiere de al menos uno al mes de tratamiento. No hay justificación en prolongar el tratamiento más allá de un mes en hombres que no responden a él. Un tercio de los hombres no presentará mejoría con el uso de alfa-bloqueadores y, actualmente, no hay un método para predecir qué hombres presentarán una buena respuesta (Bautista, y otros, 2003).

Estudios previos comparando el uso de alfa-bloqueantes al placebo mostraron una mayor probabilidad de éxito en la retirada de la sonda vesical de demora, después de un episodio de retención urinaria. Como el resultado, muchos urologistas adoptan esta práctica. El efecto parece ser independiente del tipo de alfa-bloqueador estudiado (Averbeck, y otros, 2010).

\section{Tratamiento combinado}

La investigación del efecto de una terapia de combinación con finasterida y doxazosina sobre la PIP en pacientes con BPU / LUTS. Los resultados mostraron que el volumen prostático total (TPV) y el volumen de la zona de transición (TZV) de la próstata disminuyeron significativamente después de la terapia de combinación de 6 meses $(\mathrm{P}<0.05)$, mientras que no se observaron cambios significativos en la IPP en ese punto $(\mathrm{P}>0.05)$. Las tasas de fracaso de la medicación difirieron significativamente entre los cuatro grupos. El estudio indicó que la terapia de combinación con 
finasterida y doxazosina no pudo reducir el grado de PIP. Los pacientes con LUTS / BPH con IPP que contribuyen al fracaso de la medicación tienden a tener un mayor riesgo de progresión. Liu, et al., (2017).

El tratamiento combinado fue superior al tratamiento con cada medicamento aisladamente en la reducción de la puntuación de síntomas (AUA), en aumentar la tasa media de flujo urinario máximo y en reducir la probabilidad de retención urinaria aguda y cirugía (Averbeck, y otros, 2010).

El tratamiento inicial para casos leves y moderados es medicamentoso, con el uso de alfabloqueadores o inhibidores de la 5-alfa-reductasa, o aún la combinación de éstos. Pacientes que no responden al tratamiento con medicamentos, con síntomas graves, o que desarrollan complicaciones de la HBP deben considerarse para el tratamiento quirúrgico (Averbeck, y otros, 2010).

Los resultados del estudio MTOPS, que tuvo un período de seguimiento de 4,5 años, mostraron que la combinación de finasterida a la doxazosina puede traer beneficios al paciente (Bautista, $\mathrm{y}$ otros, 2003).

\section{c) Agentes fito-terapéuticos}

El uso de fito-terapéuticos en el tratamiento de STUI y HBP es popular en Europa y Estados Unidos. Estos agentes están compuestos de varios extractos de plantas y es siempre difícil identificar que los componentes tienen mayor actividad biológica (De la Rosette, y otros, 2006). Algunos ensayos clínicos aleatorizados, con corto período de seguimiento, mostraron eficacia clínica sin mayores efectos colaterales para compuestos como la Pygeum africanum y la Serenoa repens (Wilt T. , y otros, 2002), (Wilt \& Ishani, 1998).

\section{Prostatitis aguda y crónica}

Las infecciones pueden ser agudas o crónicas, de naturaleza casi siempre bacteriana y son mucho menos comunes que la entidad no infecciosa en síndromes de dolor pélvico crónico (conocida en el pasado como prostatitis crónica). Los estudios más importantes en la evaluación de un paciente con prostatitis son los cultivos cuantitativos de localización bacteriológica y el examen microscópico de la orina segmentada y de secreción prostática exprimida (SPE), con arreglo a lo descrito por Meares (1968). 
Gema M. Barreto-Pincay; José F. Barreto-Loor; Julio D. Cevallos-Villamar; Luis A. Giler-Saltos; Mary I. VincesZambrano; Hernán D. Toro-Barrera

La prostatitis comprende las anomalías infecciosas y no infecciosas de la próstata. El cuadro clínico inicial de la prostatitis crónica bacteriana es más inconstante porque hay episodios recurrentes de cistitis que se acompañan en ocasiones de dolor pélvico y perineal. En el caso de un varón con un cuadro inicial de cistitis recurrentes, habrá que buscar un foco prostático (Scher, 2012).

\section{Tratamiento recomendado}

Los antibióticos recomendados en la prostatitis bacteriana crónica y el SDPC inflamatorio son el ciprofloxacino y levofloxacino que se consideran fármacos de elección debido a su perfil de seguridad y a sus propiedades farmacocinéticas favorables además de poseer actividad antibacteriana frente a patógenos gramnegativos como la Pseudomona aeruginosa. Johansen, et al., (1998). En la prostatitis aguda, algunos pacientes necesitan drenaje vesical, preferentemente con una sonda suprapúbica. Se ha observado un efecto positivo de la resección transuretral de próstata y la ablación transuretral con aguja en pacientes con molestias intensas (Darenkov, Simonov, Kuz'min, \& Koshkarov, 1989).

Se ha comunicado que un tratamiento combinado con un alfa-bloqueante y antibióticos depara una mayor tasa de curación que los antibióticos sólo en el SDPC inflamatorio. Se trata de la opción de tratamiento preferida por muchos urólogos (BARBALIAS \& LIATSIKOS, 1998).

\section{Cáncer de próstata}

El cáncer de próstata es una malignización del tejido prostático, de lento desarrollo que se caracteriza por un desequilibrio entre las reacciones de división y muerte celular de las células prostáticas (Schalken \& van Leenders, 2003). Más del 90\% del cáncer de próstata son adenocarcinomas que provienen de las células epiteliales secretoras. Éstas contienen receptores de andrógenos en su superficie, por tanto, son andrógenos dependientes (Filella, Alcover, Molina, \& Ballesta, 2003).

Los síntomas urinarios en los pacientes con cáncer de próstata no difieren de aquellos que tienen hiperplasia de próstata, tanto en la sintomatología urinaria obstructiva baja como en la irritativa, por lo que la diferencia entre ambas entidades nosológicas básicamente es la exploración física del paciente y la toma de estudios de laboratorio y gabinete con la finalidad de llegar al diagnóstico adecuado de esta patología (Villanueva, 2009). 
Datos recogidos de autopsias, aporta que entre el 30-40\% de los hombres mayores de 50 años presentan evidencia histológica de la enfermedad y llegando aproximadamente hasta el 70\% en los hombres mayores de 70 años (Moorthi, Kathiresan, Kiran, \& Manavalan, 2011). Parece ser que los tumores bien diferenciados, órgano-confinados y de pequeño volumen, presentan baja agresividad y que por tanto no se beneficiarían de un diagnóstico precoz (Uribe Arcila, 2005).

Podemos observar en él distintas fases de progresión:

- Enfermedad localizada, el tumor está confinado dentro de la cápsula de la próstata y no se ha dispersado hacia otras partes del cuerpo. El cáncer de próstata denominado primario es dependiente de andrógenos, tanto para crecer como para persistir y sobrevivir.

- Entre esta fase localizada, y la siguiente (enfermedad metastásica) a medio camino podemos definir la enfermedad recurrente, la cual, un tumor tras la terapia localizada, presenta signos de recidiva (típicamente un aumento de PSA).

- Enfermedad metastásica, el tumor ya está creciendo fuera de la próstata y áreas circundantes.

- Enfermedad refractaria a hormonas, englobamos en este grupo, al cáncer de próstata que continúa creciendo a pesar del tratamiento quimioterápico, medicamentos que producen la ablación de las hormonas masculinas (es decir, estamos inhibiendo andrógenos/testosterona necesarias para el crecimiento de las células de dicho tumor).

La cirugía radical del cáncer de próstata localizado en estadío avanzado es raramente curativa [199]. 199 (Moorthi, Kathiresan, Kiran, \& Manavalan, 2011)

El cáncer de próstata es único y especial entre los tumores sólidos, es un tumor en el cual la mayor amenaza para la supervivencia del paciente y su calidad de vida está dada por la metástasis al hueso, más que la enfermedad visceral en sí misma. Una vez diagnosticado el cáncer de próstata, su progresión es particularmente lenta. En los casos de enfermedad metastásica, la supresión hormonal consigue controlar la enfermedad una media de 2 a 4 años, hasta que la enfermedad recidiva, y vuelve a progresar, momento desde el cual la media de supervivencia es de 1-2 años (Schalken \& van Leenders, 2003). [198].

El cáncer de próstata se ha convertido en un problema de salud pública por su alta incidencia. El cáncer de próstata en EEUU es la neoplasia más frecuente en el varón, y la segunda causa de muerte 
Gema M. Barreto-Pincay; José F. Barreto-Loor; Julio D. Cevallos-Villamar; Luis A. Giler-Saltos; Mary I. VincesZambrano; Hernán D. Toro-Barrera

por cáncer, después del de pulmón. En España es el tercero en frecuencia y el tercero en mortalidad, tras el cáncer de pulmón y de colon. Su incidencia está en aumento en países desarrollados debido fundamentalmente a dos factores, como son la determinación del PSA en programas de detección precoz, que ha aumentado el número de diagnósticos subclínicos, y por otro lado el progresivo envejecimiento de la población. Otro factor a considerar es el aumento del consumo de grasas saturadas (Sher, 2008).

\section{Diagnósticos o pruebas complementarias}

Diversos cambios se han presentado en los últimos años, en el diagnostico oportuno de otras neoplasias, sin embargo, en relación al Cáncer de Próstata, los elementos diagnósticos siguen sin cambios a pesar del advenimiento de los años. Los elementos más importantes siguen siendo la toma de Antígeno Prostático Específico, Ultrasonido Transrectal de Próstata, Tomografía Abdominopelvico y Gamagrama Óseo (Villanueva, 2009).

Ultrasonido Transrectal de Próstata: Considerado hasta el día de hoy como el elemento ideal para el estudio integral del parénquima prostático, no solo por su alta sensibilidad y especificidad, ya que permite la toma de biopsias en aquellos pacientes en los que se presentan alguna duda en el diagnostico, sin embargo, la única disyuntiva sigue siendo el costo elevado del estudio (Villanueva, 2009).

El tacto rectal sigue siendo la prueba inicial más utilizada en el diagnóstico del cáncer de próstata, aunque muy poco sensible. Tiene grandes limitaciones, pues el tacto es subjetivo, ya que está muy influenciado por la experiencia del clínico, correcta técnica, colaboración del paciente y nivel de sospecha. Definiciones de la lesión palpada como "grande" "pequeña" "difuso" "focal" son difícilmente reproducibles en la práctica clínica. Foster, et al., (1999). En el tacto rectal, el explorador busca identificar el tamaño, la consistencia y las anomalías del interior y exterior de la glándula. Muchas neoplasias aparecen en la zona periférica de la misma y se pueden palpar durante el tacto rectal (Sher, 2008).

El antígeno prostático específico PSA, es una glicoproteína producida casi exclusivamente por el epitelio glandular prostático. Los valores normales de PSA sérico están comprendidos entre rangos 
de referencia de 0-4 ng/ml. En este rango la probabilidad de cáncer es muy baja, sobre todo con un tacto rectal normal (Sher, 2008).

Antígeno Prostático Específico: Descubierto en la década de los 70’s, producto de una violación, es hasta la fecha el marcador ideal en el diagnóstico de ésta entidad, aunque en ultimas fechas se ha observado que no es tan específico, se considera un glicoproteína de $34 \mathrm{Kd}$ con una vida media de 2.2 a 3.2 días, los valores de referencia continúan siendo los mismos del 0.0 a $4.0 \mathrm{ng} / \mathrm{ml}$, sin embargo, pueden elevarse por otras entidades patológicas teniendo inclusive un valor falso $(+)$ en el mismo (Villanueva, 2009).

A efectos prácticos, tiene especificidad de órgano, pero no de cáncer. Por tanto, las concentraciones séricas pueden aumentar en presencia de hipertrofia benigna de próstata, prostatitis y otras enfermedades no malignas. El valor de PSA como variable independiente es un mejor factor predictivo de cáncer que los hallazgos sospechosos en el tacto rectal o la ecografía transrectal (Catalona, y otros, 1994). Hay muchos equipos diferentes de análisis comercial para determinar el PSA, pero no existen valores de referencia internacionales aceptados de forma generalizada (Semjonow, Brandt, Oberpenning, Roth, \& Hertle, 1996).

Con el fin de intentar mejorar el rendimiento diagnóstico de los elementos "clásicos" de cribado (PSA y ecografía transrectal) se han hecho en los últimos años multitud de estudios, y se han ido introduciendo nuevos métodos (ecografía transrectal en 3D, color doppler, power doppler y contraste ultrasonográfico) para completar a los usados inicialmente y que permitan un enfoque diagnóstico más adecuado del paciente con sospecha clínica de cáncer de próstata (Hanahan \& Weinberg, 2000).

Tomografía Axial Computada: Se considera como un estudio de extensión en los pacientes ya que permite tener una estadificación de actividad ganglionar en pacientes que serán sometidos a Prostatectomía Radical por estadios iniciales (Villanueva, 2009).

Los métodos de imágenes han evolucionado rápidamente, mostrando cada vez mayores beneficios en el diagnóstico y seguimiento de los pacientes con cáncer de próstata. Tradicionalmente la ETR ha sido utilizada como guía para la toma de biopsias prostáticas, mientras que la tomografía computada (TC) ha tenido un papel destacado en la estadificación general (con escasa precisión para la 
Gema M. Barreto-Pincay; José F. Barreto-Loor; Julio D. Cevallos-Villamar; Luis A. Giler-Saltos; Mary I. VincesZambrano; Hernán D. Toro-Barrera

estadificación locorregional). No obstante, en la actualidad, los avances técnicos en resonancia magnética $(\mathrm{RM})$ proporcionan una imagen morfológica detallada y de alta resolución, que permite localizar la lesión y estadificarla de forma más certera, con la posibilidad, además, de obtener información funcional del tumor mediante secuencias ponderadas en difusión, dinámicas con contraste y espectroscopia (Bonekamp, Jacobs, El-Khouli, Stoianovici, \& Macura, 2011).

Gamagrama Óseo: Estudio invasivo por la aplicación de radiofármacos dentro de los cuales el Tecnecio 99 es el ideal, pues tiene una gran afinidad por el hueso y su vida promedio de 6 días para eliminarse en el cuerpo, permite así valorar la presencia de metástasis óseas, en caso de diseminación hematógena (Villanueva, 2009).

\section{Prevención}

En nuestros días, al ser el segundo cáncer más común en el mundo, le permite tener múltiples opciones terapéuticas del mismo, sinembargo, esto depende de elementos del paciente aunados a lo mencionado anteriormente (Villanueva, 2009).

Prostatectomía Radical: Considerada como una opción terapéutica por el aumento de la expectativa de vida en los pacientes menores de 70 años, a pesar de sus efectos adversos ampliamente conocidos en el mundo, como son la Disfunción Eréctil, Incontinencia Urinaria, Estenosis de Uretra, los cuales han mejorado notablemente por la presencia de nuevas modalidades dentro de la técnica quirúrgica ya sea clásica o laparoscópica (Villanueva, 2009).

Resección Transuretral de Próstata: A pesar de no ser considerada un tratamiento de cáncer de próstata, es una buena opción en aquellos pacientes con retención urinaria y obteniendo material para estudio histopatológico (Villanueva, 2009).

Castración Quirúrgica: Gracias a los estudios de Huggins en 1948 al descubrir la relación hormonodependiente a la Testosterona, en el Cáncer de Próstata, se utiliza como una modalidad terapéutica en países como el nuestro, a pesar de efectos adversos como la disminución de la libido, bochornos, disfunción eréctil (Villanueva, 2009).

Los resultados de varios estudios grandes, doble ciego, con asignación al azar de quimioprevención, se estableció que los inhibidores de la reductasa 5 alfa (5ARI) son el tratamiento principal para 
disminuir el riesgo futuro de diagnóstico de cáncer. El Prostate Cancer Prevention Trial (PCPT), en el que varones mayores de 55 años de edad recibieron el 5ARI finasterida, inhibidor de la isoforma tipo 1 de la enzima, o placebo, mostró una reducción del $25 \%$ en la prevalencia por período de cáncer prostático en todos los grupos de edad a favor de la finasterida $(18,4 \%)$ sobre el placebo $(24,4 \%)$ (Sher, 2008).

Agonistas LHRH: Estos agentes como el Leuprolide, en forma mensual o trimestral, presentan niveles de castración similares a los quirúrgicos por una desensibilización de las gonadotropinas hipofisiarias, lamentablemente el costo elevado del medicamento hacen que sea poca efectiva su utilidad (Villanueva, 2009).

En el estudio REDUCE se observó una reducción similar de $23 \%$ en la prevalencia durante el periodo de cuatro años a favor de la dutasterida. Este fármaco inhibe las isoformas tipos 1 y 2 de 5ARI. Estos resultados difieren del estudio SELECT que incluyó varones de raza negra $\geq$ a 50 años y $\geq$ a 55 años de edad; no mostró diferencia en la incidencia de cáncer entre los pacientes que recibieron vitamina $\mathrm{E}(4,6 \%)$ o selenio $(4,9 \%)$ solos o combinados $(4,6 \%)$ en relación con placebo (4,4\%); tampoco se observó ningún beneficio con la vitamina $\mathrm{E}$, vitamina $\mathrm{C}$ y el selenio en el Physicians Health Study II (Sher, 2008).

Antiandrógenos: Medicamentos como la Flutamida y la Nilutamida, actúan por bloqueo de los Receptores de la dihidrotestosterona, produciendo así niveles bajos de testosterona sérica, sin embargo, no son tan efectivos como monoterapia y deben de ir combinados con agonistas LHRH e inclusive producen efectos adversos como alteraciones en la función hepática y diarrea (Villanueva, 2009).

Radioterapia: Considerada como una buena opción para pacientes con Cáncer de Próstata localizado y en estadios C; ya sea en forma externa o intersticial con aplicación de semillas. A pesar de que sus efectos adversos continúan siendo ampliamente conocidos como la Disfunción Eréctil, migración de las semillas (Villanueva, 2009).

De todas maneras, dado que los factores que más contribuyen en el riesgo de desarrollarlo son la edad y los antecedentes familiares, la FDA ha hecho una serie de "recomendaciones" para la detección precoz del tumor (Carter, 2005). 
Gema M. Barreto-Pincay; José F. Barreto-Loor; Julio D. Cevallos-Villamar; Luis A. Giler-Saltos; Mary I. VincesZambrano; Hernán D. Toro-Barrera

a. en varones mayores de 50 años, se recomienda la determinación anual de PSA y un tacto rectal;

b. en individuos afroamericanos o con antecedentes familiares se recomiendan ambos estudios desde $\operatorname{los} 40$ años.

\section{Influencia del factor dietético}

Comparaciones internacionales concluyen que hay una relación entre la incidencia de cáncer de próstata y la ingesta de grasas en la dieta, conclusión sostenida por estudios de migración y por la creciente incidencia de cáncer de próstata en Japón, donde el consumo de grasas animales ha aumentado. Armstrong y Doll encontraron que las muertes por cáncer de próstata en 32 países estaban altamente correlacionadas con el consumo total de grasas (Klein, 1995).

Existen importantes diferencias geográficas en la incidencia de cáncer de próstata a lo largo del mundo que sugieren que algunos factores dietéticos pueden influir en el desarrollo del cáncer, bien jugando un papel activador o bien como inhibidor de la carcinogénesis (Denis, Morton, \& Griffiths, 1999).

Tres componentes dietéticos han sido estudiados en relación con el desarrollo del cáncer de próstata: grasas dietéticas, betacarotenos y vitamina A. Estudios de laboratorio han mostrado que los n-6ácidos grasos estimulan y que los 3-n-ácidos grasos inhiben las células del cáncer de próstata en cultivos de tejidos (Conde, 2005).

Adlercreutz y colaboradores han establecido que algunos componentes de las dietas mediterránea y asiática protegerían contra el desarrollo del cáncer de próstata, y que la carencia de estos compuestos en la dieta occidental, constituiría un importante factor para el desarrollo de esta enfermedad (Adlercreutz, 1990).

Aunque los tomates son la principal fuente de licopeno, en el estudio "Auckland sobre Próstata", el consumo de tomates crudos no se asoció con reducción en el riesgo de padecer cáncer de próstata. Sin embargo, muchos de los derivados del tomate como la salsa de espaguetis, sopa de tomate y salsa Ketchup son mejores fuentes de licopeno biodisponible que los tomates frescos (Hirayama, 1986). 
El selenio a diferentes dosis, tiene diferentes actividades anticarcinogénicas incluyendo protección antioxidante, freno del metabolismo carcinogénico, estimulación inmunitaria y apoptosis (Clark, y otros, 1996).

Ingesta elevada de productos ricos en selenio y la vitamina E, podrían prevenir el cáncer prostático por su capacidad antioxidante (Grover \& Martin, 2002).

La vitamina $\mathrm{E}$ tiene una potente actividad antioxidante, y también protegería contra el cáncer estimulando funciones inmunitarias, disminuyendo la actividad de la proteína $\mathrm{C}$ kinasa (involucrada en la regulación de la proliferación celular) e induciendo apoptosis. Por otro lado se ha visto que esta inhibe el crecimiento de varias líneas celulares de cáncer de próstata (Romero Cagigal, Ferruelo Alonso, \& Berenguer Sánchez, 2003).

Existen estudios que indican que la forma activa de la Vitamina D, la 1,25 dihidroxicolecalciferol o calcitrol, a dosis bajas estimula el crecimiento de células LNCaP, mientras que a dosis altas inhibe la carcinogénesis prostática (Peehl, y otros, 1994).

Los metabolitos de la Vitamina D inducen diferenciación e inhiben proliferación celular, entre otras, de líneas celulares de cáncer de próstata (Konety, Johnson, Trump, \& Getzenberg, 1999).

\section{Conclusiones.}

Las principales consideraciones en pacientes sometidos a cirugía prostática deben ser por lo tanto con el propósito de prevención y cura de la infección, el empleo de los tratamientos en las dosis adecuadas y durante el período óptimo. En tal sentido es importante considerar la naturaleza y las complejas interrelaciones entre las distintas estructuras o componentes celulares, para que durante el proceso de valoración del paciente sometido a cirugía se de formal cumplimiento a todos los protocolos con la implementación de las herramientas necesarias con el fin de establecer un consenso en el diagnóstico y tratamiento tanto para la hiperplasia prostática benigna (BPH), cuya fisiopatología, epidemiología e historia natural no se comprende completamente, para las infecciones de prostatitis las mismas que pueden ser agudas o crónicas, de naturaleza casi siempre bacteriana, así como para el cáncer de próstata mismo que es una malignización del tejido prostático, no existe hasta la presente un parámetro único y confiable que permita definir con 
Gema M. Barreto-Pincay; José F. Barreto-Loor; Julio D. Cevallos-Villamar; Luis A. Giler-Saltos; Mary I. VincesZambrano; Hernán D. Toro-Barrera

precisión estas patologías, los síntomas e índices de calidad de vida son parámetros subjetivos y por lo tanto, significativamente variables. Por consiguiente, los resultados del diagnóstico permiten deducir la identificación del paciente en base a los factores de riesgo específicos, consecuente con esto surge la necesidad de continuar ampliando los conocimientos de esta fisiología prostática con el propósito de encontrar el mejor tratamiento terapéutico. Es de importancia considerar el autocuidado puesto que esta marca diferencias significativas respecto a la asistencia habitual en la mejora de la sintomatología, mantener periódicamente la correcta de vigilancia. Además, muchos de los problemas están relacionados con la calidad de vida de los individuos afectados. Es de considerar el progresivo envejecimiento de la población. Otro factor a considerar es el aumento del consumo de grasas saturadas perjudiciales en todo aspecto para la salud de ahí la importancia de la atención médica.

\section{Bibliografia.}

Adlercreutz, H. (1990). Western diet and Western diseases: some hormonal and biochemical mechanisms and associations. Scandinavian Journal of Clinical and Laboratory Investigation, 50(201), 3-23.

Aguilar-Barradas, J., García-Irigoyen, C., Manzanilla-García, H., Castro-Ibarra, M., MartínezHernández, M., \& Acevedo-García, C. (2010). Correlational study of body mass index, abdominal perimeter and prostate gland volume in patients with obstructive urinary symptomatology due to prostate growth. Revista Mexicana de Urología, 70(3), 141-145.

Andersen, J. T., Ekman, P., Wolf, H., Beisland, H., Johansson, J., Kontturi, M., \& Scandinavian BPH Study Group. (1995). Can finasteride reverse the progress of benign prostatic hyperplasia? A two-year placebo-controlled study. Urology, 46(5), 631-637.

Andriole, G., \& Kirby, R. (2003). Safety and tolerability of the dual $5 \alpha$-reductase inhibitor dutasteride in the treatment of benign prostatic hyperplasia. European urology, 44(1), 82-88.

Averbeck, M. A., Blaya, R., Seben, R., Lima, N., Denardin, D., Fornari, A., \& Rhoden, E. (2010). Diagnóstico e tratamento da hiperplasia benigna da próstata. Revista da AMRIGS, 54(4), 471-477.

BARBALIAS, G. A., \& LIATSIKOS, E. (1998). Alpha-blockers for the treatment of chronic prostatitis in combination with antibiotics. The Journal of urology, 159(3), 883-887.

Bartsch, G., Rittmaster, R., \& Klocker, H. (2002). Dihydrotestosterone and the concept of $5 \alpha-$ reductase inhibition in human benign prostatic hyperplasia. World journal of urology, 19(6), 413-425. 
Bautista, O. M., Kusek, J., Nyberg Jr, L., McConnell, J., Bain, R., Miller, G., \& Lepor, H. (2003). Study design of the Medical Therapy of Prostatic Symptoms (MTOPS) trial. Controlled clinical trials, 24(2), 224-243.

Berry, S. J., Coffey, D., Walsh, P., \& Ewing, L. (1984). The development of human benign prostatic hyperplasia with age. The Journal of urology, 132(3), 474-479.

Bonekamp, D., Jacobs, M., El-Khouli, R., Stoianovici, D., \& Macura, K. (2011). Advancements in MR imaging of the prostate: from diagnosis to interventions. Radiographics, 31(3), 677-703.

Brown, C. T., Yap, T., Cromwell, D., Rixon, L., Steed, L., Mulligan, K., \& Emberton, M. (2007). Self management for men with lower urinary tract symptoms: randomised controlled tria. $l$. Bmj, 334(7583), 25.

Carter, H. (2005). Cáncer Próstata, Oncología clínica, ed. M. Abeloff, et al., Elsevier España, 285.

Casado, J., \& Moyano, A. (2011). Recomendaciones de la OMS para Hiperplasia Benigna de Próstata. Evaluación diagnóstica de los varones con STUI. Guías Prácticas en Urología., 2, 11.

Catalona, W., Hudson, M., Scardino, P., Richie, J., Ahmann, F., Flanigan, R., \& Waters, W. (1994). Selection of optimal prostate specific antigen cutoffs for early detection of prostate cancer: receiver operating characteristic curves. The Journal of urology, 152(6 Part 1), 2037-2042.

Chicharro-Molero, J. A., Burgos-Rodriguez, R., Sanchez-Cruz, J., del Rosal-Samaniego, J., RoderoCarcia, P., \& Rodriguez-Vallejo, J. (1998). Prevalence of benign prostatic hyperplasia in Spanish men 40 years old or older. The Journal of urology, 159(3), 878-882.

Chute, C. G., Panser, L., Girman, C., Oesterling, J., Guess, H., Jacobsen, S., \& Lieber, M. (1993). The prevalence of prostatism: a population-based survey of urinary symptoms. The Journal of urology, 150(1), 85-89.

Clark, L. C., Combs, G., Turnbull, B., Slate, E., Chalker, D., Chow, J., \& Krongrad, A. (1996). Effects of selenium supplementation for cancer prevention in patients with carcinoma of the skin: a randomized controlled trial. Jama, 276(24), 1957-1963.

Conde, A. L. (2005). Cáncer de próstata. Cirugía Urología, 186.

Darenkov, A. F., Simonov, V., Kuz'min, G., \& Koshkarov, I. (1989). Transurethral electroresection in chronic prostatitis and its complications. Urologiia i nefrologiia, (1), 18-23.

De la Rosette, J., Alivizatos, G., Madersbacher, S., Sanz, C., Nordling, J., \& Emberton, M. (2006). Guidelines on benign prostatic hyperplasia. UPDATE.

Denis, L., Morton, M., \& Griffiths, K. (1999). Diet and its preventive role in prostatic disease. European urology, 35(5-6), 377-387.

Donohue, J. F., Sharma, H., Abraham, R., Natalwala, S., Thomas, D., \& Foster, M. (2002). Transurethral prostate resection and bleeding: a randomized, placebo controlled trial of role 
Gema M. Barreto-Pincay; José F. Barreto-Loor; Julio D. Cevallos-Villamar; Luis A. Giler-Saltos; Mary I. VincesZambrano; Hernán D. Toro-Barrera

of finasteride for decreasing operative blood loss. The Journal of urology, 168(5), 20242026.

Drake, M. J. (2016). Results from the reduce trial on the effect of prostate size on incident lower urinary tract symptoms in men with mild to no current symptoms: do they justify prophylactic intervention? Translational andrology and urology, 5(5), 799.

Esteban, G. (2013). Actualización, hipertrofia prostática benigna. Evidencia actualización de la practica epidemiológica, pagina 143, 143.

Filella, X., Alcover, J., Molina, R., \& Ballesta, A. (2003). Antígeno prostático específico y sus formas moleculares. Tratado de oncología urológica. Barcelona: Sanidad y Ediciones SL.

FOLEY, S. J., SOLOMAN, L., WEDDERBURN, A., KASHIF, K., SUMMERTON, D., BASKETTER, V., \& HOLMES, S. (2000). A prospective study of the natural history of hematuria associated with benign prostatic hyperplasia and the effect of finasteride. The Journal of urology, 163(2), 496-498.

Gandhi, J., Weissbart, S., Kim, A., Josh, G., Kaplan, S., \& Khan, S. (2018). Consideraciones clínicas para la protrusión prostática intravesical en la evaluación y el tratamiento de la obstrucción de la salida de la vejiga secundaria a hiperplasia prostática benigna. Curr Urol., 12 (1), 6-12.

García Torrelles, M., Carrascosa Lloret, V., Beltrán Armada, J., Rodrigo Guanter, V., Verges Prosper, A., Rubio Tortosa, N., \& Morales Suarez-Varela, M. (2007). Resultados del tratamiento quirúrgico de la patología prostática benigna en pacientes geriátricos. Archivos Españoles de Urología (Ed. impresa), 60(1), 23-30.

García, R. C. (2014). Relación entre el antígeno prostático específico y la hiperplasia prostática benigna en pacientes mexicanos. Estudio REPSA. Revista Mexicana de Urología, 74(6), $342-345$.

González Calvar, S. I., Salcedo, J., \& Martínez Mangini, M. (2005). Últimos avances en el diagnóstico de la hiperplasia benigna de próstata. Acta bioquímica clínica latinoamericana, 39(2).

Grossfeld, G. D., \& Coakley, F. (2000). Benign prostatic hyperplasia: clinical overview and value of diagnostic imaging. Radiologic Clinics of North America, 38(1), 31-47.

Grover, P. L., \& Martin, F. (2002). The initiation of breast and prostate cancer. Carcinogenesis, 23(7), 1095-1102.

Hanahan, D., \& Weinberg, R. (2000). The hallmarks of cancer. cell, 100(1), 57-70.

Hirayama, T. (1986). A large scale cohort study of dietary habits and cancer mortality. Gan no rinsho. Japan journal of cancer clinics, 32(6), 610-622.

Holtgrewe, H., Nielsen, H., \& Carlsson, P. (1997). the 4th International Consultation on BPH. 6381. 
Klein, E. A. (1995). An update on prostate cancer. Cleveland Clinic journal of medicine, 62(5), $325-$ 338.

Konety, B. R., Johnson, C., Trump, D., \& Getzenberg, R. (1999). Vitamin D in the prevention and treatment of prostate cancer. In Seminars in urologic oncology (Vol. 17, No. 2, pp. 77-84).

Krivoborodov, G., Efremov, N., \& Bolotov, A. (2017a). Indicadores ecográficos de la próstata, vejiga urinaria y parámetros de uroflujometría en el diagnóstico de obstrucción infravesical en hombres con hiperplasia prostática benigna. Urologiia, (5), 9-14.

Krivoborodov, G., Efremov, N., \& Bolotov, A. (2017b). Protrusión prostática intravesical en el diagnóstico de obstrucción infravesical en hombres con hiperplasia prostática benigna. Urologiia. (2), 105-109.

Lepor, H. (2004). Pathophysiology, epidemiology, and natural history of benign prostatic hyperplasia. Reviews in urology, 6(Suppl 9), S3.

Marberger, M. J., Andersen, J., Nickel, J., Malice, M., Gabriel, M., Pappas, F., \& Waldstreicher, J. (2000). Prostate Volume and Serum Prostate-Specific Antigen as Predictors of Acute Urinary Retention. European urology, 38(5), 563-568.

Moorthi, C., Kathiresan, K., Kiran, K., \& Manavalan, R. (2011). In-vitro cell based assay: a preferred anticancer drug screening techniques for the academic researchers. $J$ Pharmacy Res, 4(3), 671-675.

Parsons, J. K., Sarma, A., McVary, K., \& Wei, J. (2013). Obesity and benign prostatic hyperplasia: clinical connections, emerging etiological paradigms and future directions. The Journal of urology, 189(1), S102-S106.

Peehl, D. M., Skowronski, R., Leung, G., Wong, S., Stamey, T., \& Feldman, D. (1994). Antiproliferative effects of 1, 25-dihydroxyvitamin D3 on primary cultures of human prostatic cells. Cancer Research, 54(3), 805-810.

Roehrborn, C. G., Boyle, P., Nickel, J., Hoefner, K., \& Andriole, G. (2002). Efficacy and safety of a dual inhibitor of 5-alpha-reductase types 1 and 2 (dutasteride) in men with benign prostatic hyperplasia. Urology, 60(3), 434-441.

Roehrborn, C. G., Bruskewitz, R., Nickel, G., Glickman, S., Cox II, C., Anderson, R., \& Holtgrewe, H. (2000). Urinary retention in patients with BPH treated with finasteride or placebo over 4 years. European urology, 37(5), 528-536.

Romero Cagigal, I., Ferruelo Alonso, A., \& Berenguer Sánchez, A. (2003). Dieta y cáncer de próstata. Actas Urológicas Españolas, 27(6), 399-409.

Schalken, J. A., \& van Leenders, G. (2003). Cellular and molecular biology of the prostate: stem cell biology. Urology, 62(5), 11-20.

Scher, H. I. (2012). Enfermedades benignas y malignas de la próstata. Harrison "Principios de Medicina Interna, 1, 17. 
Gema M. Barreto-Pincay; José F. Barreto-Loor; Julio D. Cevallos-Villamar; Luis A. Giler-Saltos; Mary I. VincesZambrano; Hernán D. Toro-Barrera

Semjonow, A., Brandt, B., Oberpenning, F., Roth, S., \& Hertle, L. (1996). Discordance of assay methods creates pitfalls for the interpretation of prostate-specific antigen values. The Prostate, 29(S7), 3-16.

Sher, H. (2008). Benign and Malignant Disease of the prostate, Principles of Internal Medicine. McGraw-Hill Medical, Vol. 17th.

Suzuki, T., Otsuka, A., \& Ozono, S. (2016). La combinación de protrusión prostática intravesical e índice de resistencia es útil para predecir la obstrucción de la salida de la vejiga en pacientes con síntomas del tracto urinario inferior que sugieren hiperplasia prostática benigna. Asociación Japonesa de Urología, Int J Urol., 23 (11), 929-933.

Uribe Arcila, J. F. (2005). Cáncer de Próstata.¿ Por qué se produce el cáncer de próstata?. Aproximación a un modelo genético y molecular. Revista Urología Colombiana, 14(3).

Villanueva, O. (2009). Fundamentos de Oncología/Cáncer de próstata. UNAM, México, D.F: Facultad de Estudios Superiores Zaragoza.

Wiechers, L. L., \& Cuéllar, H. (2007). La próstata como riesgo principal en la aplicación de un tratamiento hormonal sustitutivo. Revista de Endocrinología y Nutrición, 15(1), 19-23.

Wilt, T. J., \& Ishani, A. (1998). Pygeum africanum for benign prostatic hyperplasia. Cochrane database of systematic reviews, (1).

Wilt, T., Ishani, A., Stark, G., Mac Donald, R., Mulrow, C., \& Lau, J. (2002). Serenoa repens for benign prostatic hyperplasia (Cochrane Review). The Cochrane Library, (3).

Zael, S. R., Santiago, F., Víctor, H., Héctor, C., Pérez-Becerra, R., Alejandro, U., \& Dorian, S. (2010). Morbilidad de la prostatectomía radical, complicaciones quirúrgicas tempranas y sus factores de riesgo; experiencia en el Hospital General Dr. Manuel Gea González. Revista Mexicana de Urología, 70(5), 278-282. 